\title{
Psycho-Behavioral Intervention Model for Effective Sustainable Awareness in Green Development.
}

\author{
Rostam Yaman ${ }^{1 \& 3}$, Kespanerai Kokchang ${ }^{1}$, Noraini Ahmad ${ }^{2}$, Farrah Zuhaira Ismail $^{3}$. \\ ${ }^{1}$ Environment Research Institute, Chulalongkorn University, Bangkok, Thailand. \\ ${ }^{2}$ Kulliyah of Architecture \& Environmental Design, IIUM, Malaysia. \\ ${ }^{3}$ Faculty of Architecture Planning \& Surveying, UiTM, Malaysia.
}

\begin{abstract}
This research addressed an appropriate way to promote sustainable behavior by intervening psycho-behavioral awareness to promote green inclination psychological characteristics. The main objective of this study aimed to determine the effectiveness of a psycho-behavioral intervention model on the occurrence of sustainable awareness and positive behavior in tertiary education students. A pretest and post-test control group design provided an understanding of the extent to which psychological characteristics can have an impact on 220 interior architecture students in increasing sustainable awareness and positive behavior after training. The major finding indicated that interior architecture students who received psycho-behavioral intervention model gained greater psychological characteristics and sustainable awareness and also showed greater positive behavior than the control group after training. It can be concluded that psycho-behavioral intervention can promote sustainable awareness and positive behavior.
\end{abstract}

\subsection{Introduction}

Tertiary education institutions play an important role in influencing the present and future of sustainable behavior and lifestyles of their students [1]. This role has also been acclaimed that the formal modules of higher education institutions can substantially influence students' behavioral and attitude responses. Psychological factors and pro-environmental behavioral might enhance not only current subjective of well-being but expectations of future subjective of well-being. These suggested that psycho-behavioral factors both as antecedents and consequences act a significant influencing role in encouraging a sustainable society and improving quality of life [2].

Conventionally, the tertiary education for sustainable design have been implemented in the form of lectures and design projects as evaluation. Typically, lecturers presented the sets of information about sustainable design criteria in order to provide students an understanding of knowledge to motivate their behavioral. The evaluation in measuring the deliverance of the imparted knowledge however does not really measure the sustainable awareness of the students but instead just measuring the student's ability to transfer the gained knowledge into a design projects. If the evaluation is measure in the form of conventional written test or examination, the impact probably not profound enough to lead to sustainable awareness practice but merely for memorizing to get through the evaluations. Hence, this methodology is not based on any comprehensive theoretical framework and yielded little transformation in sustainable behavior [3].

Numerous environmental setbacks are imbedded via human behavioral, and thus, can be controlled by encouraging pro-environmental behavioral [4]. Challenges in improvising environmental quality via behavioral changes will be more successful if a person chooses a behavior that substantially influences environmental quality, then analyzes which factors may cause those behavioral, and lastly employs and assesses interventions that transform these antecedents and the behavioral $[5 ; 6]$. 
Few models on psychological focus in academic promotion such as 'social learning theory' by Bandura (1977) [7] and 'health belief model theory' by Rosenstock (1974) [8] is a basis for psychobehavioral development in education. According to Bauman et. al. (1993) [9], these models targeted at the development of knowledge, traits and skills in developing students positive pro-behavioral lifestyles.

This research are based on the Punthumanavin's (1994) [10] moral theory and; Ma-oon (2013) [11] psycho-behavioral training model and psychological characteristics. The intervention module model delivery was adapted and developed based on both of these theories. The conducted study dwelve five psychological traits: knowledge on sustainable awareness and pro-environmental behavior, attitudes toward sustainable awareness and pro-environmental behavior, future orientation in sustainable awareness and pro-environmental behavior, self-control in sustainable awareness and pro-environmental behavior, and belief in the internal locus of control in sustainable awareness and pro-environmental behavior. The findings have indicated that how sustainable awareness and pro-environmental behavior can be more effectively implemented in a tertiary level education setting.

\subsection{Research Framework}

From the concept of this study, the conceptual framework was synthesized as shown in Figure 1.

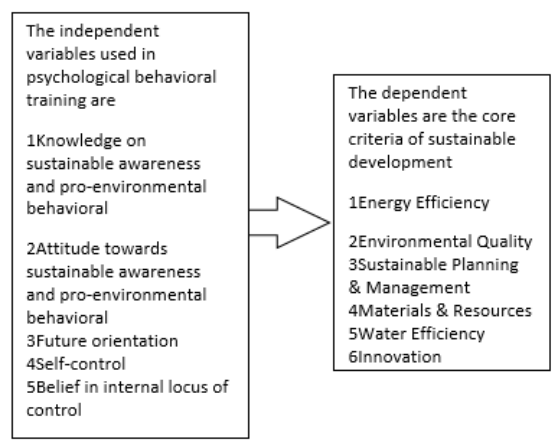

Fig. 1 Conceptual framework showing the relationships of variables used in this research (adapted from Ma-oon, 2013).

\subsection{Objectives}

The objectives of this research is to find out the efficacy of psycho-behavioral instruction on the practices of sustainable awareness and proenvironmental behavior in tertiary education students. The identifiable objectives were:

1. To identify the level of five psychological characteristics and sustainable awareness and proenvironmental behavior at pre-training.

2. To study the correlation between psychological characteristics and sustainable awareness and proenvironmental behavior.

3. To assess the effectiveness of psycho-behavioral post-training on the practices of sustainable awareness and pro-environmental behavior in the tertiary education.

\subsection{Methodology}

This study was divided into two phases.

Phase 1: Aimed to study the level of students' psychological characteristics, sustainable awareness and pro-environmental behavior before attending the module provided by identifying the psychological characteristics as causal factors of sustainable awareness and pro-environmental behavior. The samples, obtained randomly, consisted of 220 tertiary education students (110 from group AP2475A and 110 from group AP2475B) Center of Studies for Interior Architecture, Faculty Architecture, Planning \& Surveying, Universiti Teknologi MARA. The designed questionnaire was divided into two parts: Part A was designed to study the bio-social background of the students and part B was designed to assessed five psychological characteristics and six aspects of sustainable awareness and proenvironmental behavior. The data were analyzed using the percentage, mean, standard deviation and correlation coefficient.

Phase 2: The module model was developed with interventions, based on the conventional Program Educational Objective (PEO) and Program Learning Outcome (PLO) of Green Interior (INA536) course for Bachelor Interior Architecture (Hons.) - AP247:

1. Study of the principles, theories and related research on sustainable awareness and proenvironmental behavior in order to provide basic information and to utilize the searched information to 
develop the module model and construct the activities.

2. Development of the sustainable awareness and pro-environmental module model for INA536 Green Interior coursework and also the findings discovered in item 1 above. The module model consisted of 10 weekly activities, with two hours face to face activities to complete all module model.

3. Implementation of the module model to all respondents (220 samples) who registered for INA536 course.

Phase 3: The effectiveness of the module model was assessed. The samples, obtained using purposive sampling via INA536 Green Interior course student registration are made up of 220 students from Universiti Teknologi MARA (UiTM) located in Puncak Alam, Selangor, who volunteered to participate in the study. A pre-test and post-test evaluation was assessed. The students were assigned into experimental (AP2475A) and control groups (AP2475B). The data were collected two timesbefore implementation of the intervention module and after the completion of module. The feedback was analyzed by percentage, mean, standard deviation, t-test and analysis of variance. The methodology is shown in Figure 2.

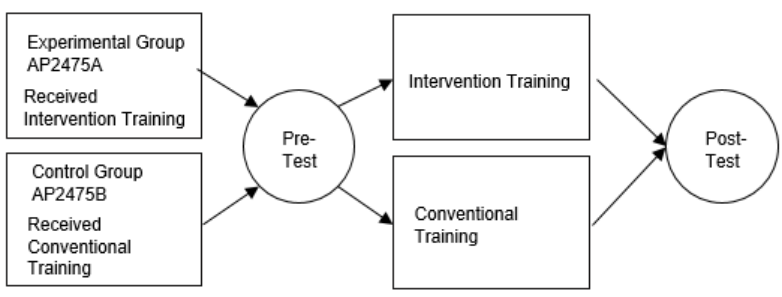

Fig. 2. Steps of the experiment

Note: Conventional Training refers to the activities provided to the control group in testing throughout the research. However, these trainings are non-interventions module model and were not hands-on to sustainable awareness and pro-environmental.

\subsection{Results}

Phase 1: The level of the students' psychological traits and sustainable awareness and proenvironmental behavior were at the medium and low level and the five psychological traits were the causal factors of students' sustainable awareness and proenvironmental behavior, (Table 1). In addition, the correlation values indicated that the psychological traits were the casual factors of sustainable awareness and pro-environmental behavior, (Table 2).

Table 1. Level of psychological traits, sustainable awareness and pro-environmental behavior

\begin{tabular}{|c|c|c|c|c|c|c|}
\hline $\begin{array}{l}\overrightarrow{0} \\
\stackrel{0}{0}\end{array}$ & $\begin{array}{l}8 \\
\frac{80}{0} \\
\frac{0}{3} \\
0 \\
1 \\
1\end{array}$ & 兽 & 莺 & 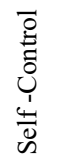 & 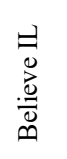 & 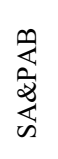 \\
\hline HIGH & 39.1 & 40.2 & 39.1 & 33.5 & 28.5 & 29.6 \\
\hline MEDIUM & 41.8 & 48.0 & 41.8 & 39.2 & 47.0 & 48.9 \\
\hline LOW & 19.1 & 11.8 & 19.1 & 27.3 & 24.5 & 21.5 \\
\hline
\end{tabular}

Table 2. Correlations values indicating psychological traits as causal factors of sustainable awareness \& proenvironmental behavior

\begin{tabular}{lc}
$n$ & \\
\hline traits 110 & SA-PAB \\
\hline Knowledge & $.32^{* * *}$ \\
\hline Attitude & $.45^{* * *}$ \\
\hline Future Orientation & $.25^{* * *}$ \\
\hline Self-Control & $.48^{* * *}$ \\
\hline Believe In Internal Locus Of Control & $.44^{* * *}$ \\
\hline$* * * p<.001$ &
\end{tabular}

Phase 2: The delivery model comprised of two major parts. Part A was the content of delivery model which emphasizes on the five psychological traits as the causal factors of students' sustainable awareness and pro-environmental behavior. Part B was the process of the intervention module delivery, with emphasis on being student-centered. The intervention module model is shown in Figure 3.

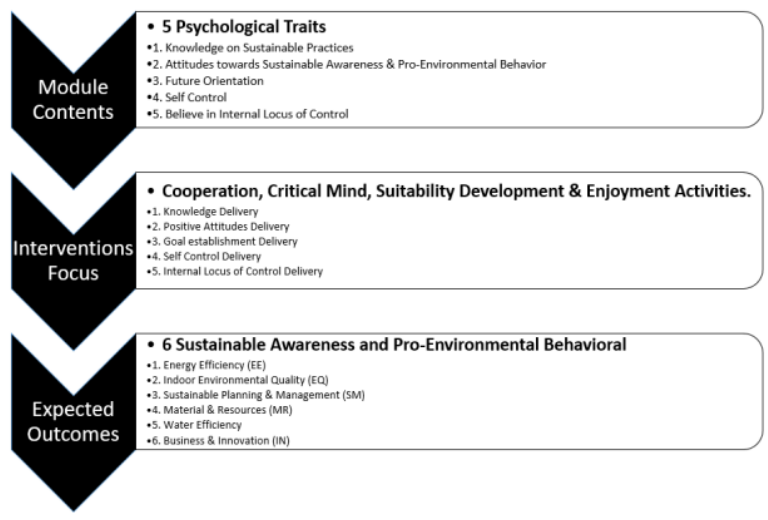

Fig. 3. Invention Module Model used in this study 
Upon completion of module delivery, students shall have more of the five psychological traits compared before delivery with significance statistical level of .001 (Table 3). The AP2475A (experimental group) gained intervened psychological traits at a higher level than the AP2475B (control group). After full module delivery, the students who had undergone intervention model had acquired more sustainable awareness and pro-environmental behavior than the control group (Table 4).

Table 3. Mean comparison of psychological traits in AP2475A (experimental group) before and after intervention module delivery

\begin{tabular}{cccccc}
\hline \multirow{2}{*}{ Traits } & \multicolumn{2}{c}{$\begin{array}{c}\text { Before Module } \\
\text { Delivery } \\
N=110\end{array}$} & \multicolumn{2}{c}{$\begin{array}{c}\text { After Module } \\
\text { Delivery } \\
N=110\end{array}$} & \multirow{2}{*}{$\begin{array}{c}\text { T-Test } \\
\text { Value }\end{array}$} \\
\cline { 2 - 5 } & $X$ & $S d$ & $X$ & $S d$ & \\
\hline Knowledge & 28.32 & 4.39 & 32.60 & 4.81 & $13.14^{* * *}$ \\
\hline Attitude & 63.05 & 9.24 & 73.16 & 8.23 & $2.41^{* *}$ \\
\hline $\begin{array}{c}\text { Future } \\
\text { Orientation }\end{array}$ & 57.18 & 5.62 & 63.53 & 7.36 & $4.47^{* * *}$ \\
\hline $\begin{array}{c}\text { Self } \\
\text { Control }\end{array}$ & 90.38 & 12.22 & 103.51 & 11.47 & $7.14^{* * * *}$ \\
\hline $\begin{array}{c}\text { Believe In } \\
\text { Internal } \\
\text { Locus Of } \\
\text { Control }\end{array}$ & 54.20 & 5.71 & 57.01 & 6.92 & $4.27^{* * * *}$ \\
\hline
\end{tabular}

Table 4. Comparison of mean scores between experimental and control groups of five psychological characteristics measured after training

\begin{tabular}{|c|c|c|c|c|c|}
\hline \multirow[t]{2}{*}{ Traits } & \multicolumn{2}{|c|}{$\begin{array}{c}\text { Ap2475a } \\
\text { (Experimental. } \\
\text { Group) } \\
N=110\end{array}$} & \multicolumn{2}{|c|}{$\begin{array}{c}\text { Ap2475b } \\
\text { (Control } \\
\text { Group) } \\
N=110\end{array}$} & \multirow[t]{2}{*}{$\begin{array}{l}T \text {-Test } \\
\text { Value }\end{array}$} \\
\hline & $X$ & $S d$ & $X$ & $S d$ & \\
\hline Knowledge & 27.50 & 49.86 & 24.82 & 4.52 & $2.41^{*}$ \\
\hline Attitude & 74.68 & 7.51 & 67.77 & 6.83 & $2.53 *$ \\
\hline $\begin{array}{c}\text { Future } \\
\text { Orientation }\end{array}$ & 58.35 & 4.82 & 53.65 & 4.34 & $2.02 *$ \\
\hline Self Control & 53.88 & 5.41 & 51.93 & 5.74 & $2.15^{*}$ \\
\hline $\begin{array}{l}\text { Believe In } \\
\text { Internal } \\
\text { Locus Of } \\
\text { Control }\end{array}$ & 95.50 & 11.61 & 91.15 & 8.47 & $2.19 *$ \\
\hline
\end{tabular}

The correlation factor value of five psychological traits between sustainable awareness and proenvironmental behavior of AP2475A (experimental group) was higher than AP2475B (control group). The relationships between the psychological traits measured after completed intervention module delivery yielded higher value of the experimental group than the control group (Table 5).

Table 5. Correlation value comparison on five psychological traits and sustainable awareness and proenvironmental behavior of AP2475A (experimental group) and AP2475B (control group) after training

\begin{tabular}{ccc}
\hline & \multicolumn{2}{c}{$\begin{array}{c}\text { Correlation Values }(R) \\
\text { SA\&PEB }\end{array}$} \\
\cline { 2 - 3 } Psycho-Behavioral Traits & $\begin{array}{c}\text { Ap2475a } \\
(\text { Experimental }) \\
n=110\end{array}$ & $\begin{array}{c}\text { Ap2475b } \\
\text { (Control) } \\
n=110\end{array}$ \\
\hline Knowledge & $.31 * * *$ & .11 \\
\hline Attitude & $.38^{* * *}$ & $.21 *$ \\
\hline Future Orientation & $.23^{* * *}$ & $.21^{*}$ \\
\hline Self Control & $.21^{* * *}$ & .13 \\
\hline Believe In Internal Locus Of Control & $.40^{* * *}$ & .17 \\
\hline$* p<.05, * * * p<.001$ & &
\end{tabular}

\subsection{Discussion}

The study outcomes indicated that the five psychological traits were the casual factors of students' sustainable awareness and proenvironmental behavior. The students' sustainable awareness and pro-environmental behavior and the five psychological traits were at a lower significant level due to non-intervention module model delivery of psychological traits. Thus, when they delivered with intervention module model, both psychological traits and sustainable awareness and proenvironmental behavior increased to a higher significant level. This indicated that the Intervention Module Model is applicable to deliver positive traits and pro-environmental behavior students that benefits themselves and society as a whole.

The outcomes also showed that the delivery model was effective in instilling and nurturing sustainable awareness and pro-environmental behavior. Hence, this had validated that the Intervention Module Model, grounded on the psychological traits are the casual factors of positive psycho-behavioral provided an appropriate method is adopted. In this study, it was verified that the knowledge level of the students was low before the module delivery, hence, it is essential for the knowledge to be instilled in the students.

\subsection{Conclusion}

Tertiary education students who received intervention module model in psychological traits-which are, i) knowledge about sustainable awareness and proenvironmental behavior; ii) attitude towards sustainable awareness and pro-environmental 
behavior; iii) future orientation; iv) self-control; and v) belief in internal locus of control had obtained both psychological traits and sustainable awareness and pro-environmental behavior comparable to students who are not delivered with intervention module model. Specifically, the correlations between psychological traits and sustainable awareness and pro-environmental behavior were significant in the experimental group (AP2475A) that received intervention module model compared to conventional module delivery in the control group (AP2475B). Therefore, in order to deliver a model of psychological traits associated with module delivery in nurturing sustainable awareness and proenvironmental behavior, all five psychological traits must be considered for effective psycho-behavioral. The study conclusion can be seen in Figure 4.

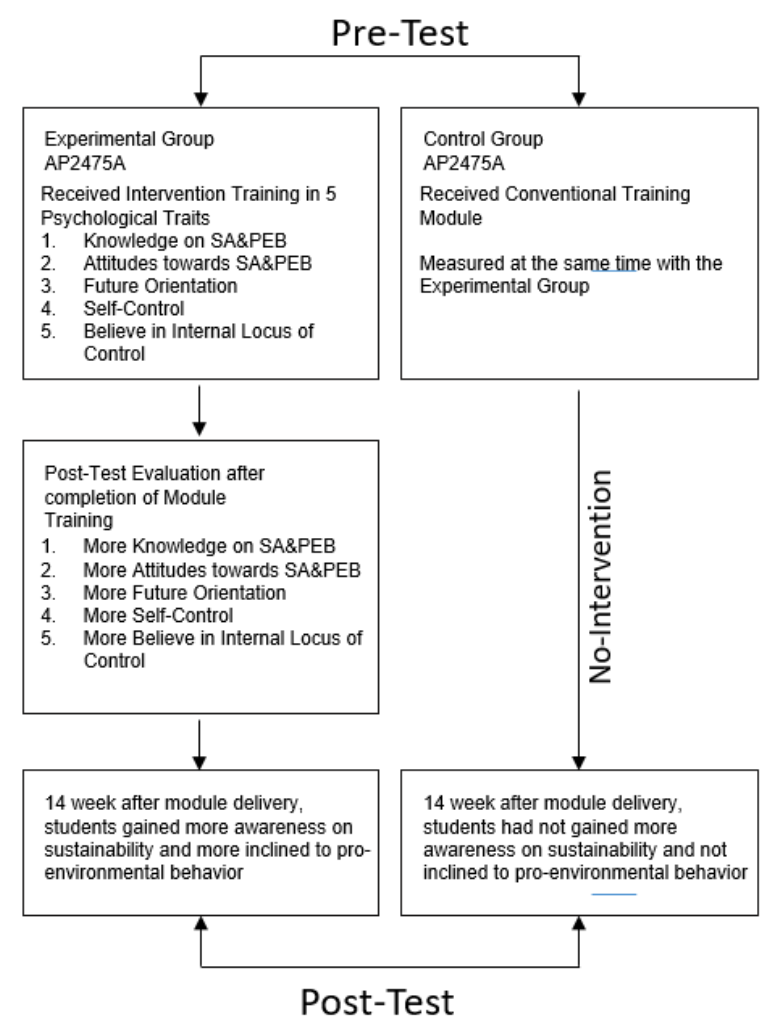

Fig. 4. Intervention Module Delivery Model

\section{References}

1. A.M. Aleixo, U.M. Azeiteiro, \& S. Leal, Toward sustainability through higher education: Sustainable development incorporation into Portuguese higher education institutions. In Challenges in Higher Education for Sustainability, 159-187 (2016)

2. N. Kaida, \& K. Kaida, Pro-environmental behavior correlates with present and future subjective well-being. Environment, development and sustainability, 18(1), 111-127 (2016)

3. L. Green, \& F. Levis, Measurement and evaluation in health education and promotion. Palo Alto, CA: Mayfield, (1986)

4. A. M. Nordlund, \& J. Garvill. Value structures behind proenvironmental behavior. Environment and behavior, 34(6), 740-756 (2002)

5. E. S. Geller, The challenge of increasing proenvironment behavior. Handbook of environmental psychology, 2, 525-540 (2002)

6. L. Steg, \& C. Vlek. Encouraging proenvironmental behaviour: An integrative review and research agenda. Journal of environmental psychology, 29(3), 309-317 (2009)

7. A. Bandura, Social learning theory. Englewood Cliffs, NJ, USA: Prentice Hall. (1977)

8. I. Rosenstock. Historical Origin of Health Belief Model. Health Education Monograph, 15(2), 470-473 (1974)

9. A. Bauman, D. Nutbeam, \& M. Wise, Goal and targets for Australia's Health in the year 2000 and beyond. Canberra: Commonwealth Department of Health, Housing \& Community Services, AGPH, (1993)

10. D. Punthumanawin, Moral theory for Thai people: Research and Development Srinakarintharavirot University, Bangkok. [in Thai] (1994)

11. R. Ma-oon, Effectiveness of Psycho-Behavioral Training Model on Health Promotion and Disease Prevention Behavior in Middle School Students. Kasetsart J. (Soc. Sci) 34, 573 - 582 (2013) 